\title{
Effect of "Positive Hearth Deviance" on feeding practices and underweight prevalence among children aged 6-24 months in Quetta district, Pakistan: A comparative cross sectional study
}

\author{
Novera Nishat $^{1}$, Iram Batool $^{1}$ \\ Sri Lanka Journal of Child Health, 2011; 40: 57-62 \\ (Key words: Positive hearth deviance; feeding practices; lady health workers; knowledge)
}

\begin{abstract}
Objectives: To compare the feeding practices and underweight prevalence of hearth children with those of non hearth children.

Method: A comparative cross sectional study was carried out from 1st April to 30th June 2009. The study population comprised mothers with children aged 6-24 months and of the same socioeconomic and cultural ties from two areas of Quetta District, Pakistan. The "Multi Level Random Sampling Technique" was used. Hearth mothers comprised those who attended hearth sessions (2006-2008) in the hearth area. Data was collected using a structured questionnaire and analyzed using Epi-Info version 3.3.2 and SPSS version 17.0 for windows.
\end{abstract}

Results: The total study population was 200 mothers and the response rate was $95 \%$. There was a statistically significant difference between the hearth and non hearth areas regarding age groups $(\mathrm{P}<0.01)$, education of mothers $(\mathrm{P}<0.05)$, male: female ratio of children $(\mathrm{P}<0.05)$, weighing of babies at birth $(\mathrm{P}<0.05)$, age for initiation of complementary feeds $(\mathrm{P}<0.01)$, feeding practices of mothers $(\mathrm{P}<0.01)$ and underweight prevalence $(\mathrm{P}<0.001)$.

Conclusion: Feeding practices are significantly better and underweight prevalence significantly less in hearth mothers compared to non hearth mothers.

${ }^{1}$ Health Services Academy, Faculty of Medicine, Quaid-e-Azam University, Islamabad, Pakistan

(Received 5 August 2010: Accepted 27 August 2010)

\section{Introduction}

Malnutrition remains a major public health problem throughout the developing world and is an underlying factor in over $50 \%$ of children under the age of 5 years who die each year of preventable causes ${ }^{1}$. In most countries, the occurrence of malnutrition rises sharply during the age period 6-18 months and the deficits acquired at this age are difficult to compensate for later in childhood ${ }^{2}$. However, a comparison of average nutrient intakes of children aged 6-24 months and new dietary reference intakes published by the Institute of Medicine, USA shows that the diets of infants and young children of 6-24 months of age in most lowincome countries are consistently deficient in some nutrients, including iron, zinc and vitamins $^{3}$.

In accordance with the global movement of millennium development goals (MDGs) for enhancement of health facilities, the Government of Pakistan initiated the "Prime Ministers National Programme for Family Planning and Primary Health Care" in April 1994. As an integral part of this project, the concept of the 'Lady Health Worker' (LHW) was introduced. LHWs from all over Pakistan are trained, supervised and then paid to serve their own community or area. LHWs can provide preventive, curative and rehabilitative services to the community.

Pakistan, being a signatory of "Alma Ata Declaration 1978 (Health for All)" was bound to meet MDG 4, i.e. reduction of childhood mortality due to malnutrition, by the year $2000^{5}$. As a major step forward, Mercy Corps, a nongovernmental organisation (NGO), started a project called "Positive Hearth Deviance" in selected areas of Baluchistan. The project is currently operational in district Quetta only. In 
the first phase the project has been piloted in 8 out of 33 Basic Health Units ${ }^{6}$.

Positive Deviance / Hearth Nutrition Programme is a home-based and neighbourhood-based nutrition programme for children who are at risk for protein-energy malnutrition in developing countries. The programme uses the "positive deviance" approach to identify those behaviours practised by the mothers or caretakers of wellnourished children from poor families and to transfer such positive practices to others in the community with malnourished children. The "Hearth" or home is the location for the nutrition education and rehabilitation sessions?

The Positive Hearth Deviance approach has four main components viz. community participation, community mobilization towards problem solution, practical demonstration and advocacy and self help. Positive Deviance (PD) is based on the belief that in every community there are a few individuals and families whose particular practices enable them to have better health compared to their similarly impoverished neighbours. Hearth is an implementation strategy that supports caregivers to learn and practice new health behaviours together in a safe environment and rehabilitate their malnourished children. In Pakistan "positive hearth deviance" approach is being applied in Baluchistan and in some areas of Haripur on trial basis.

\section{Objectives}

1. To describe the breast and complementary feeding practices of hearth and non hearth mothers with children aged 6 -24 months.

2. To compare the feeding practices and underweight prevalence of children aged 624 months of hearth and non hearth mothers.

\section{Method}

A comparative cross sectional study was conducted among mothers with children aged 624 months in those communities of Quetta district in the north-west of Baluchistan province of Pakistan which were involved in 'positive hearth deviance' sessions from 2006-2008 as compared to mothers with children aged 6-24 months of those communities that were not involved in 'positive hearth deviance' sessions from 2006-2008 and were only exposed to nutritional health delivered by LHW. The study population comprised hearth and non-hearth mothers of the same socioeconomic and cultural ties from 2 urban slum areas. The sampling technique used for this study was the "Multi Level Random Sampling Technique". Key points of this are:

- At the first level 2 LHWs were selected randomly from the study area.

- At the second level, the first house from the community was selected using the Bottle method and then the next houses were selected using systematic random sampling.

- At the third level in case there was no child aged 6- 24 months in a household, the next household was included till completion of 50 cases in one LHWs catchment area.

- Random samples of 100 mothers each were selected both from the hearth and non-hearth areas. Half of the sample of respondents was selected from the catchment area of each LHW.

\section{Inclusion Criteria}

- Hearth mothers comprised those mothers (not identified as PD mothers) with children aged 6- 24 months who had attended hearth sessions (2006-2008) in the hearth area and were willing to participate in the study.

- Non-hearth mothers comprised mothers of the same socioeconomic and cultural group with children aged 6-24 months in selected non-hearth area and willing to participate in the study.

\section{Exclusion criteria}

- Mothers with children aged $<6$ months and $>2$ years.

- Mothers of children with mental retardation, congenital deformity, chronic disorders e.g. congenital heart disease, tuberculosis, and third degree malnutrition.

- Mothers included in other health promotion interventions.

Permission for research was taken from the country director of Mercy Corps, and from the Executive District Officer through a written request form. Response rate was $95 \%$, only $5 \%$ mothers refusing to participate in the study. All 
mothers fulfilling selection criteria were enrolled. Data was collected for the following variables for mothers; age, education, working status, number of children under five, child feeding practices, weight assessment in $\mathrm{kg}$ and variables of household socio-economic status were taken from the mothers in their home settings, following by informed consent. A structured questionnaire based on these variables was used. Data collection was done in 5 weeks from April 20th 2009 to May 30th 2009. Principal investigator with help of two research assistants, who were trained by principal investigator, was involved in data collection.

Data was analyzed using Epi-Info version 3.3.2 and SPSS version 17.0.for windows. The EpiInfo 2000 Nutrition program was used to analyze under weight children Z-scores. Weight data was used to calculate weight-for-age, Z-scores to measure prevalence of under weight based on the National Centre for Health Statistics/WHO reference data. Data was entered and standard steps for data analysis using descriptive statistics were undertaken.

Ethical review committee of Health Services Academy approved the said proposal. Consent was obtained from mothers, after informing them about the nature and purpose of survey. All information was kept strictly confidential. Data was used solely for the purpose of the study. There was no monetary compensation for the study participants and there were no direct benefits to the individual study participants but there will be benefit to the community.

\section{Results}

The total study population was 200 mothers and the response rate was $95 \%$. The sociodemographic characteristics of the 200 mothers from Quetta district in the hearth and non-hearth mothers are shown in table 1.

Table 1

Socio-demographic characteristics of the mothers

\begin{tabular}{|c|c|c|c|c|}
\hline \multicolumn{2}{|c|}{ Variable } & \multicolumn{2}{|c|}{ Area } & \multirow[t]{2}{*}{ P-value } \\
\hline & & Hearth (\%) & Non-Hearth (\%) & \\
\hline \multirow{3}{*}{ Age (Years) } & Less than 20 & 15 & 09 & \multirow{3}{*}{$\begin{array}{l}0.009 \\
<0.01\end{array}$} \\
\hline & $20-29$ & 51 & 73 & \\
\hline & $30-39$ & 34 & 18 & \\
\hline \multirow[b]{2}{*}{ Working status } & Housewife & 81 & 82 & \multirow{2}{*}{$\begin{array}{l}0.353 \\
>0.05\end{array}$} \\
\hline & Working & 19 & 18 & \\
\hline \multirow{4}{*}{$\begin{array}{l}\text { Education } \\
\text { (Mothers) }\end{array}$} & Uneducated & 65 & 45 & \multirow{4}{*}{$\begin{array}{l}0.026 \\
<0.05\end{array}$} \\
\hline & Primary school & 16 & 21 & \\
\hline & Secondary school & 14 & 24 & \\
\hline & University/Higher & 05 & 10 & \\
\hline \multirow{4}{*}{$\begin{array}{l}\text { Education } \\
\text { (Fathers) }\end{array}$} & Uneducated & 35 & 33 & \multirow{4}{*}{$\begin{array}{l}0.4488 \\
>0.05\end{array}$} \\
\hline & Primary school & 35 & 33 & \\
\hline & Secondary school & 24 & 20 & \\
\hline & University/Higher & 06 & 14 & \\
\hline \multirow{2}{*}{$\begin{array}{l}\text { Occupation } \\
\text { (Fathers) }\end{array}$} & Skilled & 83 & 81 & \multirow[t]{2}{*}{$>0.05$} \\
\hline & Non-skilled & 17 & 19 & \\
\hline \multirow[t]{2}{*}{ Infant Information } & Male & 58 & 77 & \multirow{2}{*}{$\begin{array}{l}0.029 \\
<0.05\end{array}$} \\
\hline & Female & 42 & 23 & \\
\hline
\end{tabular}

Majority of the participants belonged to the age group of 20-29 years. The percentages of women less than 20 years and 30-39 years were low in both hearth and non-hearth areas. There was a statistically significant difference between the two areas regarding age groups $(\mathrm{P}<0.01)$. Whilst $81 \%$ of the mothers of hearth areas were "housewives", $82 \%$ of non-hearth area mothers shared the same status. A minor percentage of the mothers were working women. There was no 
significant difference between the two areas regarding working status $(\mathrm{P}>0.05)$. Large numbers of the mothers in both areas were uneducated. Non-Hearth mothers were significantly more educated than hearth mothers $(\mathrm{P}<0.05)$. In case of the education of fathers, there was no significant difference between the two areas $(\mathrm{P}>0.05)$. Majority of the fathers questioned during this study were "skilled". Keeping in mind that we have included daily wagers, domestic servant, industrial worker, farmer, fisherman, craftsman, dealer, trader or salesperson into skilled category and policeman and civil servant in non skilled category, it was observed that almost equal numbers of the fathers were skilled in both areas. Whilst males were predominant in both areas, there was a significant difference in male: female ratio between the two comparative areas $(\mathrm{P}<0.05)$.
The total monthly income levels in the hearth and non-hearth areas are shown in Figure 1.

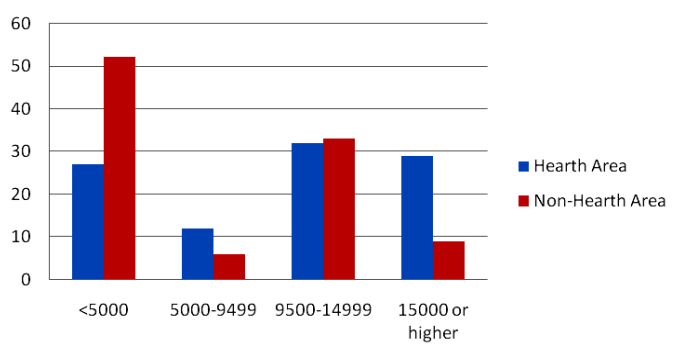

Figure 1: Income levels in hearth/non-hearth areas

Table 2 presents a cumulative result of the "breast feeding practices" of the mothers from hearth and non-hearth areas of Quetta District.

Table 2

Breast feeding practices of mothers

\begin{tabular}{|c|c|c|c|c|}
\hline \multirow{2}{*}{\multicolumn{2}{|c|}{ Variable }} & \multicolumn{2}{|c|}{ Area } & \multirow[t]{2}{*}{ P-value } \\
\hline & & Hearth (\%) & Non-Hearth (\%) & \\
\hline \multirow[t]{2}{*}{ Birth weight } & Yes & 63 & 54 & 0.023 \\
\hline & No & 37 & 46 & $<0.05$ \\
\hline \multirow[t]{2}{*}{ Child received "colostrum"? } & Yes & 90 & 79 & 0.088 \\
\hline & No & 10 & 21 & $>0.05$ \\
\hline \multirow[t]{2}{*}{ Pre-lacteal intake practices } & Yes & 55 & 61 & 0.224 \\
\hline & No & 45 & 39 & $>0.05$ \\
\hline \multirow{2}{*}{$\begin{array}{l}\text { Age for initiation of } \\
\text { complementary feeds }\end{array}$} & 4 months & 30 & 51 & 0.005 \\
\hline & 6 months & 70 & 49 & $<0.01$ \\
\hline \multirow[t]{2}{*}{ Bottle feeding practices } & Yes & 43 & 55 & 0.094 \\
\hline & No & 57 & 45 & $>0.05$ \\
\hline \multirow{2}{*}{$\begin{array}{c}\text { Ready-made complementary } \\
\text { feeding practices }\end{array}$} & Yes & 36 & 43 & 0.214 \\
\hline & No & 64 & 57 & $>0.05$ \\
\hline
\end{tabular}

Very significant numbers of infants had not been weighed at birth. In this regard there was a significant difference in the two areas $(\mathrm{P}<0.05)$. Majority of the children in this region received "colostrum" after birth. Fluids other than breast milk can have effects on the health of the child. About $55 \%$ of the children in hearth areas, and $61 \%$ in non-hearth areas received some fluid other than breast milk. There is no significant difference between the hearth and non-hearth mothers regarding pre lacteal feeding practices $(\mathrm{P}>0.05)$. About $70 \%$ mothers of hearth areas and $49 \%$ of non-hearth areas started giving solid food to their children at 6 months of age. There was a significant difference in initiation of complementary feeding in hearth and non hearth area; majority of the hearth mothers started complementary feeding at 6 months of age
$(\mathrm{P}<0.01)$. Forty three percent of the mothers in hearth areas, and 55\% in non-hearth areas bottlefeed their children. However, no statistical significance could be illustrated between the two groups as regards this practice. Similarly $64 \%$ of mothers in hearth areas and 57\% in non-hearth areas do not give ready-made food to their children.

The time of breast feeding initiation is shown in Figure 2. 


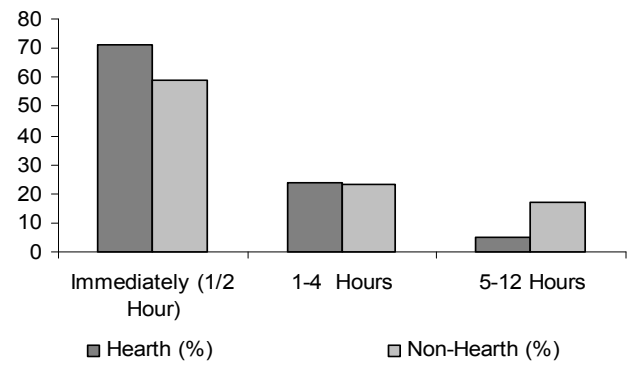

Figure 2 Breast feeding initiation

Majority of the mothers $(71 \%$ in hearth areas, $59 \%$ in non-hearth areas) started to breast-feed their children within $1 / 2$ hour after birth. The second highest percentage $(24 \%$ in hearth and $23 \%$ in non-hearth areas) was in the range of 1-4 hours. A very small number of mothers started to breast feed after 5 hours of birth. Majority of mothers in hearth and non-hearth areas had significantly high rates of breast feeding initiation within $1 / 2$ hour after birth $(\mathrm{P}<0.05)$.

Table 3 shows the summarized results for the feeding practices of the mothers of this area. Questions of a variant nature have been asked to assess those practices.

Table 3

Feeding practices

\begin{tabular}{|l|c|c|c|c|}
\hline \multicolumn{2}{|c|}{ Variable } & \multicolumn{2}{c|}{ Area } & P-value \\
\cline { 3 - 4 } \multicolumn{2}{|c|}{} & $\begin{array}{c}\text { Hearth } \\
(\mathbf{\%})\end{array}$ & $\begin{array}{c}\text { Non-Hearth } \\
(\mathbf{\%})\end{array}$ & \\
\hline Separate food preparation & Yes & 86 & 67 & 0.006 \\
\cline { 2 - 4 } & No & 14 & 33 & $<0.01$ \\
\hline \multirow{2}{*}{$\begin{array}{l}\text { What type of water do you use for } \\
\text { drinking and preparation of child food? }\end{array}$} & Boiled & 64 & 44 & 0.004 \\
\cline { 2 - 4 } & Un-boiled & 36 & 56 & $<0.01$ \\
\hline Knowledge about meat alternates & Yes & 78 & 58 & 0.006 \\
\cline { 2 - 4 } & No & 22 & 42 & $<0.01$ \\
\hline Knowledge about complementary & Yes & 80 & 50 & 0.005 \\
feeding recipes six or more & No & 20 & 50 & $<0.01$ \\
\hline
\end{tabular}

There is a significant difference in separate food preparation practices among the hearth and nonhearth areas $(\mathrm{P}<0.01)$. Similarly $64 \%$ of mothers in the hearth areas claim to give boiled water to their children compared to $44 \%$ in non-hearth areas $(\mathrm{P}<0.01)$. A general question was posed to the mothers to judge if they have sufficient knowledge about meat alternatives. Majority of the mothers knew that soya beans could be used as an alternative to meat, and the difference between the 2 areas was significant $(\mathrm{P}<0.01)$. The difference between the hearth and nonhearth areas was also significant regarding knowledge about $>6$ nutritious recipes $(\mathrm{P}<0.01)$.

Major food group intake practices by the mothers are shown in Figure 3.

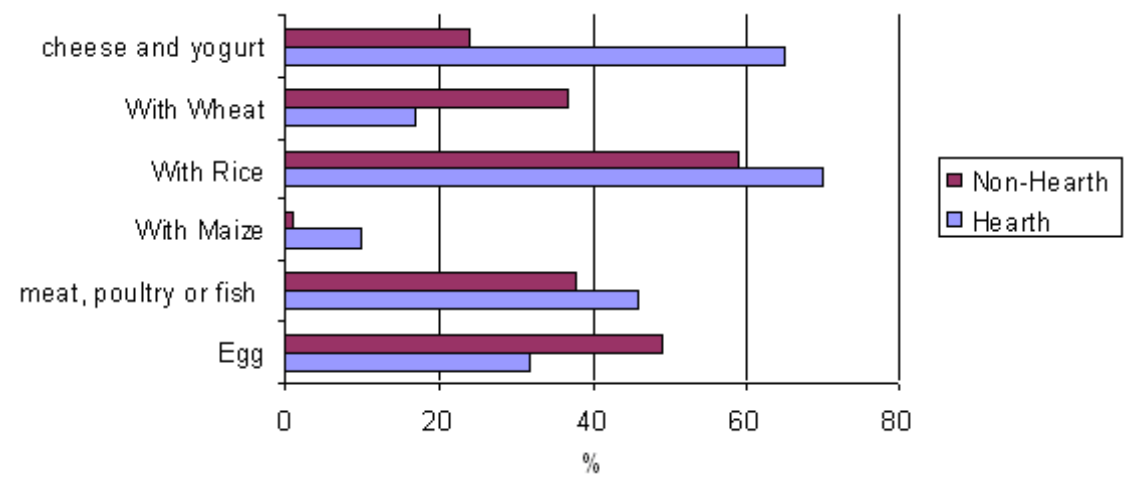

Figure 3: Major food groups intake

Thirty two percent of mothers in hearth areas and $49 \%$ in non-hearth areas were giving "egg" to their children once a week. Forty six percent of the mothers in the hearth areas and 38\% in the 
non-hearth areas were giving meat, poultry, and fish to the children once a week. In this study $65 \%$ of the mothers in the hearth areas and $24 \%$ of mothers in the non-hearth areas were giving "cheese" and "yogurt" to their children weekly.

Underweight prevalence is shown in Table 5.

Weights of children were categorized into normal weight and underweight using Z-scores for the hearth and non-hearth areas. There was a significant difference of underweight prevalence between the two areas $(\mathrm{P}<0.001)$.

Table 5

Underweight prevalence

\begin{tabular}{|l|c|c|c|}
\hline \multicolumn{1}{|c|}{ Weight } & $\begin{array}{c}\text { Hearth } \\
\text { area }\end{array}$ & $\begin{array}{c}\text { Non-hearth } \\
\text { area }\end{array}$ & P-value \\
\hline Underweight & $7.0 \%$ & $54.0 \%$ & 0.0001 \\
\hline Normal weight & $93.0 \%$ & $46.0 \%$ & $<0.001$ \\
\hline
\end{tabular}

The male: female ratio among underweight children is shown in table 6 .

Table 6

Male: female ratio among underweight children

\begin{tabular}{|l|c|c|c|}
\hline \multicolumn{1}{|c|}{ Weight } & Boy & Girl & P-value \\
\hline Underweight & $34.8 \%$ & $22.0 \%$ & 0.381 \\
\cline { 1 - 2 } Normal weight & $65.2 \%$ & $78.0 \%$ & $>0.05$ \\
\hline
\end{tabular}

Among the underweight children boys are more underweight as compared to girls collectively in both areas.

\section{Conclusions}

- Feeding practices of hearth mothers are significantly better than those of non-hearth mothers $(\mathrm{P}<0.01)$.

- Underweight prevalence is significantly lower in hearth mothers as compared to non hearth mothers $(\mathrm{P}<0.001)$.

\section{Limitations of the study}

- Due to the small sample size, findings cannot be generalized to all feeding mothers.

- Quality of the data might have been affected by the quality of the mother's records.

- Due to time constraints and insecure law and order conditions in Quetta, we were unable to get the desired large sample size.
- Due to the cross sectional study design we were unable to establish a cause and effect relationship. As the study area is an urban slum in Quetta core area of several donor funded health interventions, and definitely exposed to other nutritional health promotion sources, it is not easy to differentiate the effect of positive hearth deviance from other interventions.

\section{References}

1. Caulfield L, et al: "Under-nutrition as an underlying cause of child deaths associated with diarrhoea, pneumonia, malaria, and measles". American Journal of Clinical Nutrition 2004; 80:193-8.

2. WHO: "Joint statement on the communitybased management of severe acute malnutrition", (Cited June 14, 2009). Available from:

http://www.who.int/child adolescent health /documents/a91065/en/index.html

3. Kimmons, Joel E, et al: "Low nutrient intakes among infants in rural Bangladesh are attributable to low intake and micronutrient density of complementary foods", J Nutr 2005; 135: 444-51.

4. WHO: Pakistan's experience in Lady Health Workers Program", Regional Committee for the Eastern Mediterranean Region, 2004.

5. UNICEF: "Information by country data and statistics 2008. (Cited July 14, 2009). Available from:

http://www.unicef.org/infobycountry/southa $\underline{\text { sia.html }}$

6. Nishtar S, "Pakistan action plan on chronic diseases, public private partnership in action”, National Action Plan, 2008.

7. Child Survival Collaborations and Resources Group (CORE) Nutrition Working Group February 2003, Positive Deviance / Hearth: A resource guide for sustainably rehabilitating malnourished children. Available from:

http://www.positivedeviance.org/pdf/manual s/Positive\%20Deviance \%20hearth.pdf 